\title{
Ultrapure Dialysis Fluid and Response to Hepatitis B Vaccine
}

\author{
H. Schiffla $\quad$ H. Wendinger ${ }^{a} \quad$ S.M. Lang ${ }^{b}$ \\ ${ }^{a}$ Kuratorium für Dialyse und Nierentransplantation, Dialysezentrum München-Laim, München, \\ bMedizinische Klinik Innenstadt, Ludwig-Maximilians Universität München, München, Deutschland
}

Dear Sir,

Hepatitis B virus infection has remained a serious threat to maintenance hemodialysis patients in spite of improvements in infection control and dialysis techniques. Multiple reasons may explain the persistence of this problem. Hemodialysis patients are at a greater risk of infection, the seroconversion rate after vaccination is still less than in the general population (50-75 versus $95 \%$ ) and the duration of immunity is shorter [1].

The lack of response to hepatitis B vaccine may arise from reduced costimulation and effector activation of $\mathrm{T}$ cells and correlates with an increased production of proinflammatory cytokines by monocytes [2, 3]. There is considerable evidence that endotoxin fragments and other bacterial products derived from contaminated dialysis fluid can cross dialyzer membranes and induce enhanced cytokine release by monocyte activation [4]. This cytokine release may be circumvented by the use of on-line produced ultrapure dialysis fluid, which results in a lower systemic inflammatory response [5, 6].

The purpose of our prospective randomized investigation was to test the hypothesis that the microbiological quality of dialysis fluid affects the response to hepatitis B vaccination.

Patients with end-stage renal disease receiving hemodialysis were eligible. Inclusion criteria were as follows: hepatitis B surface antigen (HbsAg) negative, antibody to
HbsAg negative and no previous hepatitis vaccination. Exclusion criteria were acute or chronic inflammatory disorders or infections, use of immunosuppressive drugs and malignancy. 72 early hemodialysis patients (32 female, 40 male; age $62 \pm 8$ years) gave informed consent. Patients were randomly assigned to either conventional, i.e. potentially contaminated, dialysis fluid or ultrapure dialysis fluid (produced on-line by onestep additional ultrafiltration using an endotoxin-adsorbing polysulfone filter). All patients received hemodialysis 3 times per week (Kt/V of at least 1.2) utilizing volumetrically controlled ultrafiltration (MTS 4008, Fresenius, Oberursel, Germany) and high-flux polysulfone dialyzers (APS 650 Asahi, Tokyo, Japan). The vaccination schedule encompassed four doses of $40 \mu \mathrm{g}$ of recombinant hepatitis B vaccine (Gen H-BVax D, Aventis Pasteur MSD, Leimen, Germany) given at $0,1,2$ and 6 months in the deltoid muscle. Antibody titers to HbsAg were measured by the AUSAB IMX system (Abbott Laboratories, Chicago, Ill., USA) one month after the last dose. An antibody titer of $10 \mathrm{IU} / 1$ or more represented seroconversion. The nonconverters were those who did not reach an antibody titer of $10 \mathrm{IU} / 1$ or more after completion of the vaccination program. Laboratory tests [hemoglobin, intact parathyroid hormone (PTH), serum albumin], calculation of body mass index and EPO doses were determined as previously described [7]. Statistical significance was calculated for differences between means using an unpaired $t$ test and for observed/expected frequencies by means of $\chi^{2}$ analysis (twotailed Fisher's exact test). A p value of less than 0.05 was considered significant. All values in tables are expressed as means \pm SD.

There were no statistically significant differences in age, gender, body weight, etiology of renal disease, time on hemodialysis, $\mathrm{Kt} / \mathrm{V}$, hemoglobin concentration, number of patients receiving EPO, intact PTH levels or parameters of nutritional status between the two study groups. The ultrapure dialysis fluid group, however, had significantly lower CRP and IL-6 concentrations and need for rHuEPO (table 1).

The overall seroconversion rate was $78 \%$ (56 out of 72 patients). Of these 56, 32 patients were in the ultrapure dialysis fluid group and 24 patients were in the conventional mildly contaminated dialysis fluid group ( 89 vs. $67 \%$; Fisher's exact two-tailed test, $\mathrm{p}=0.045)$. The antibody titers obtained 4 weeks after the last vaccination dose were significantly higher in the ultrapure dialysis fluid group (table 2). In 8 out of the 12 nonresponding patients of the conventional dialysis fluid group, seroconversion was achieved by a second vaccination protocol (identical to the first) after switching to ultrapure dialysis fluid.

Our prospective randomized investigation demonstrates that the use of ultrapure

\begin{tabular}{ll}
\hline KARGER & ( ) 2002 S. Karger AG, Basel \\
0028-2766/02/0913-0530\$18.50/0 \\
$\begin{array}{l}\text { Fax +4161306 12 34 } \\
\begin{array}{l}\text { E-Mail karger@karger.ch } \\
\text { www.karger.com }\end{array}\end{array}$ & $\begin{array}{l}\text { Accessible online at: } \\
\text { www.karger.com/journals/nef }\end{array}$
\end{tabular}

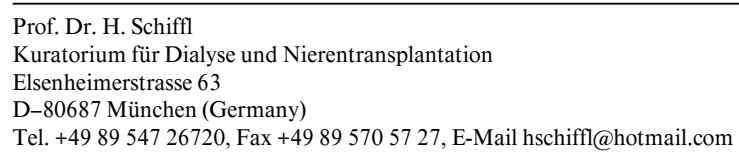


dialysis fluid results in a higher seroconversion rate in response to intramuscular vaccination against hepatitis B virus in early maintenance hemodialysis patients. The differences in the rate of seroconversion between the two groups could not be explained by differences in the demographic or renal characteristics of the two study groups. Moreover, there was no evidence of underdialysis, malnutrition, excessive hyperparathyroid hormone secretion or lower incidence of rHuEPO therapy. Our data indicate that endotoxins derived from mildly contaminated dialysis fluid are related to increased cytokine release by monocyte activation and contribute to the uremia-associated immune defect.

In the past, a number of measures have been taken to increase the seroconversion rate and duration of immunity against hepatitis $B$ virus vaccination in end-stage renal disease patients [1]. They consisted of an increased number of doses, increased antigen load per dose, different routes of administration (intradermally vs. intramuscularly), addition of IL-2 to the protocol or vaccination earlier in the course of progressive renal failure. However, these different approaches have not been successful in a reproducible way. However, any decrease in the incidence of hepatitis B virus infection depends exclusively on immunity to hepatitis B virus infection by successful vaccination [8]. Ultrapure dialysis offers a safe and cost-efficient strategy to increase the immunity to hepatitis $B$ in end-stage renal disease.

In conclusion, the present investigation demonstrated for the first time that a high conversion rate and high titer response to hepatitis B vaccination can be achieved in end-stage renal disease patients treated with ultrapure dialysis fluid.

\section{References}

1 Rangel MC, Coronado VG, Euler GL, Strikas RA: Vaccine recommendations for patients on chronic dialysis. The Advisory Committee on Immunization Practices and the American Academy of Pediatrics. Semin Dial 2000;13: 101-107.

2 Sester U, Sester M, Hauk M, Kaul H, Kohler $\mathrm{H}$, Girndt M: T-cell activation follows Th1 rather than Th2 patterns in haemodialysis patients. Nephrol Dial Transplant 2000;15:12171223

Ultrapure Dialysis Fluid and Response to

Hepatitis B Vaccine
Table 1. Patient characteristics at recruitment

\begin{tabular}{lll}
\hline & $\begin{array}{l}\text { Ultrapure dialysis } \\
\text { fluid group }\end{array}$ & $\begin{array}{l}\text { Conventional dialysis } \\
\text { fluid group }\end{array}$ \\
\hline Number of patients & 36 & 36 \\
Age, years & $64 \pm 10$ & $60 \pm 6$ \\
Gender (female/male) & $15 / 21$ & $17 / 19$ \\
BMI, kg/m² & $24 \pm 3$ & $26 \pm 5$ \\
Etiology of renal disease (major type) & & \\
$\quad$ Chronic glomerulonephritis & 10 & 8 \\
$\quad$ Nephroangiosclerosis & 8 & 7 \\
$\quad$ Diabetes mellitus & 4 & 8 \\
$\quad$ Polycystic kidney disease & 4 & 4 \\
Tubulo-interstitial nephritis & $6 \pm 2$ & $5 \pm 3$ \\
Time on hemodialysis, months & $1.3 \pm 0.1$ & $1.2 \pm 0.1$ \\
Kt/V & $10.4 \pm 0.6$ & $10.2 \pm 0.8$ \\
Hemoglobin, g/dl & 26 & 25 \\
Number of patients on rHuEPO & $62 \pm 4^{*}$ & $98 \pm 18$ \\
Dose of rHuEPO, U/kg/week & $104 \pm 45$ & $96 \pm 38$ \\
Intact PTH, pg/ml & $4.0 \pm 0.3$ & $3.8 \pm 0.2$ \\
Serum albumin, g/dl & $0.6 \pm 0.2^{*}$ & $1.2 \pm 0.4$ \\
CRP, mg/dl & $14 \pm 4^{*}$ & $45 \pm 6$ \\
IL-6, pg/ml & & \\
\hline & & \\
\hline
\end{tabular}

$\mathrm{BMI}=$ Body mass index.

$* \mathrm{p}<0.05$ versus corresponding values in patients receiving conventional dialysis fluid.

Table 2. Antibody titers after vaccination in responding patients receiving different dialysis fluids

\begin{tabular}{lll}
\hline & $\begin{array}{l}\text { Ultrapure dialysis } \\
\text { fluid group }\end{array}$ & $\begin{array}{l}\text { Conventional dialysis } \\
\text { fluid group }\end{array}$ \\
\hline Responders & $32 *$ & 24 \\
Antibody titer, IU/1 & $616 \pm 123^{*}$ & $268 \pm 108$ \\
\hline
\end{tabular}

$* \mathrm{p}<0.05$ versus corresponding values in patients receiving conventional dialysis fluid.
3 Girndt M, Sester M, Sester U, Kaul H, Köhler $\mathrm{H}$ : Defective expression of B7-2 (CD86) on monocytes of dialysis patients correlates to the uremia-associated immune defect. Kidney Int 2001;59:1382-1389.

4 Lonnemann G: The quality of dialysate: An integrated approach. Kidney Int Suppl 2000; 76:S112-S119.

5 Canaud B, Bosc JY, Leray H, Morena M, Stec F: Microbiologic purity of dialysate: Rationale and technical aspects. Blood Purif 2000;18: 200-213.
6 Sitter T, Bergner A, Schiffl H: Dialysate related cytokine induction and response to recombinant human erythropoietin in haemodialysis patients. Nephrol Dial Transplant 2000;15: 1207-1211.

7 Schiffl H, Lang SM, Stratakis D, Fischer R: Effects of ultrapure dialysis fluid on nutritional status and inflammatory parameters. Nephrol Dial Transplant 2001;16:1863-1869.

8 Lewis-Ximenez LL, Oliveira JM, Mercadante LA, De Castro L, Santa Catharina W, Stuver S, Yoshida CF: Serological and vaccination profile of hemodialysis patients during an outbreak of hepatitis B virus infection. Nephron 2001;87:19-26. 